\title{
Genomic and phenotypic characterisation of invasive neonatal and colonising group B Streptococcus isolates from Slovenia, 2001-2018
}

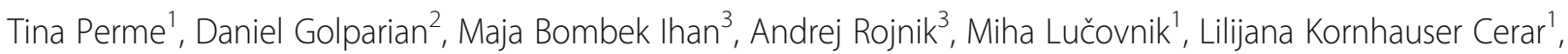
Petja Fister ${ }^{4}$, Jana Lozar Krivec ${ }^{4}$, Štefan Grosek ${ }^{1,5}$, Alojz Ihan ${ }^{6}$, Samo Jeverica ${ }^{3+}$ and Magnus Unemo ${ }^{2^{*}+}$ (D)

\begin{abstract}
Background: Group B Streptococcus (GBS) is the leading cause of invasive neonatal disease in the industrialized world. We aimed to genomically and phenotypically characterise invasive GBS isolates in Slovenia from 2001 to 2018 and contemporary colonising GBS isolates from screening cultures in 2018.

Methods: GBS isolates from 101 patients (invasive isolates) and 70 pregnant women (colonising isolates) were analysed. Basic clinical characteristics of the patients were collected from medical records. Antimicrobial susceptibility and phenotypic capsular serotype were determined. Whole-genome sequencing was performed to assign multilocus sequence types (STs), clonal complexes (CCS), pathogenicity/virulence factors, including capsular genotypes, and genome-based phylogeny.

Results: Among invasive neonatal disease patients, 42.6\% ( $n=43)$ were females, 41.5\% $(n=39 / 94)$ were from preterm deliveries ( $<37$ weeks gestation), and $41.6 \%(n=42)$ had early-onset disease $(E O D)$. All isolates were susceptible to benzylpenicillin with low minimum inhibitory concentrations (MICs; $\leq 0.125 \mathrm{mg} / \mathrm{L}$ ). Overall, 7 serotypes were identified (la, Ib, II-V and VIII); serotype III being the most prevalent (59.6\%). Twenty-eight MLST STs were detected that clustered into 6 CCs. CC-17 was the most common CC overall (53.2\%), as well as among invasive $(67.3 \%)$ and non-invasive $(32.9 \%)$ isolates $(p<0.001)$. CC-17 was more common among patients with lateonset disease (LOD) (81.4\%) compared to EOD (47.6\%) ( $p<0.001)$. The prevalence of other CCs was $12.9 \%(C C-23)$, $11.1 \%$ (CC-12), 10.5\% (CC-1), 8.2\% (CC-19), and 1.8\% (CC-498). Of all isolates, $2.3 \%$ were singletons.

(Continued on next page)
\end{abstract}

\footnotetext{
* Correspondence: magnus.unemo@regionorebrolan.se

†Samo Jeverica and Magnus Unemo joint last authors.

${ }^{2}$ WHO Collaborating Centre for Gonorrhoea and other STIs, National

Reference Laboratory for STIs, Department of Laboratory Medicine,

Microbiology, Örebro University, SE-70185 Örebro, Sweden

Full list of author information is available at the end of the article
}

(C) The Author(s). 2020 Open Access This article is licensed under a Creative Commons Attribution 4.0 International License, which permits use, sharing, adaptation, distribution and reproduction in any medium or format, as long as you give appropriate credit to the original author(s) and the source, provide a link to the Creative Commons licence, and indicate if changes were made. The images or other third party material in this article are included in the article's Creative Commons licence, unless indicated otherwise in a credit line to the material. If material is not included in the article's Creative Commons licence and your intended use is not permitted by statutory regulation or exceeds the permitted use, you will need to obtain permission directly from the copyright holder. To view a copy of this licence, visit http://creativecommons.org/licenses/by/4.0/ The Creative Commons Public Domain Dedication waiver (http://creativecommons.org/publicdomain/zero/1.0/) applies to the data made available in this article, unless otherwise stated in a credit line to the data. 


\begin{abstract}
(Continued from previous page)
Conclusions: A high prevalence of hypervirulent CC-17 isolates, with low genomic diversity and characteristic profile of pathogenicity/virulence factors, was detected among invasive neonatal and colonising GBS isolates from pregnant women in Slovenia. This is the first genomic characterisation of GBS isolates in Slovenia and provides valuable microbiological and genomic baseline data regarding the invasive and colonising GBS population nationally. Continuous genomic surveillance of GBS infections is crucial to analyse the impact of IND prevention strategies on the population structure of GBS locally, nationally, and internationally.
\end{abstract}

Keywords: Group B Streptococcus, GBS, Capsular type, Hypervirulent CC-17, Neonatal infection, Molecular epidemiology, Pathogenicity/virulence factors, Slovenia

\section{Background}

Group B Streptococcus (GBS; Streptococcus agalactiae) is the leading cause of invasive neonatal disease (IND) in industrialized world [1]. IND is divided into early-onset disease (EOD), occurring within the first week postpartum, and late-onset disease (LOD), affecting infants aged $>1$ week, mostly up to 90 days [2]. EOD can be prevented using intrapartum antibiotic prophylaxis. This is most effective when administered based on universal screening of GBS colonisation during the late third trimester of pregnancy or intrapartum [2]. In Slovenia, a less effective risk-based approach is predominantly used, which results in lower coverage of subsequent prophylaxis. This is likely the main reason for the high incidence of IND in Slovenia, estimated at 0.72/1000 live births, $0.53 / 1000$ for EOD [3].

The polysaccharide capsule is the main pathogenicity/ virulence factor of GBS [4]. Based on polysaccharide capsular antigens, GBS is divided into ten distinct serotypes (Ia, Ib, II-IX), which are antigenically and structurally distinct. The most common serotypes among GBS strains in Europe are serotypes Ia, II, III and $\mathrm{V}$; with serotype III responsible for the majority of IND cases, particularly LOD $[5,6]$. Additional pathogenicity/ virulence factors have been implicated in the GBS colonisation and development of IND, among them several surface proteins such as pili, alpha-like proteins (ALP) family, C5a peptidase ( $\mathrm{ScpB})$, laminin-binding protein (Lmb), fibrinogen-binding proteins (Fbs), serine-rich proteins (Srr), and GBS immunogenic adhesins (Bib) [6, 7]. Pathogenicity/virulence factors of hypervirulent serotype III, multilocus sequence typing (MLST) clonal complex 17 (CC-17) isolates, have been particularly well studied and include serine-rich repeat glycoprotein 2 (Srr-2) and hypervirulent GBS adhesin (HvgA allele), conferring meningeal tropism contributing to the higher prevalence among LOD patients $[8,9]$.

For typing, whole genome sequencing (WGS) provides an ideal resolution and accuracy. However, simpler typing methods, such as MLST examining allelic variation in seven slowly evolving housekeeping genes, remain frequently used [10, 11]. Using MLST, bacterial isolates are classified into sequence types (ST), which cluster into CCs based on sequence similarities [10]. The majority of human GBS isolates cluster into 5 major CCs, namely CC-1, CC-12, CC-17, CC-19, and CC-23 [12]. An increase in the incidence of IND caused by the hypervirulent $\mathrm{CC}-17$ has been previously described $[12,13]$. The rapid expansion of $\mathrm{CC}-17$ has been proposed to contribute to the limited success of current strategies to prevent IND in the industrialized world [13]. The WGS data additionally provide opportunities to characterise practically any other genotypic trait of bacterial isolates, such as the presence or absence of various pathogenicity/virulence factors, mutations, insertions, deletions or single nucleotide polymorphisms (SNPs).

In Slovenia, the prevalence of GBS colonisation among pregnant women is estimated at $17 \%$ [14], and very limited information is available about the epidemiology of neonatal GBS disease [3] and no data about the molecular epidemiology of GBS in the perinatal period exist. In the present study, all available Slovenian GBS isolates implicated in IND and a selection of contemporary colonising GBS isolates were phenotypically and genomically characterised.

\section{Methods}

\section{Patients and bacterial isolates}

This was a retrospective cohort study. Isolates from 101 neonates/infants ( $n=114$; invasive isolates) from 2001 to 2018 and 70 pregnant women $(n=71$; colonising isolates) in 2018 were analysed. Invasive isolates were from blood ( $n=96)$ and/or cerebrospinal fluid (CSF, $n=18)$ of neonates and infants aged 0-12 months. They were obtained from archived collections at all Slovenian microbiological laboratories $(n=4)$ (Supplementary Fig. 1). Based on the estimated incidence of IND in Slovenia [3], included cases represented $42 \%$ of all IND cases in Slovenia 2001-2018 (Supplementary Table 1). Basic demographic and clinical data were collected from the laboratory and hospital information systems. EOD was defined as occurring between 1 and 7 days postpartum, LOD between 8 and 90 days, and very late-onset disease (vLOD) between 91 and 365 days [2]. Colonising isolates were collected prospectively from consecutive vaginal $(n=52)$ 
or recto-vaginal $(n=19)$ screening swabs of pregnant women in 2018. All isolates were microbiologically characterized, however, only one isolate per patient was included in the analysis. If a patient had phenotypically identical GBS isolates cultured concomitantly from blood and CSF, the CSF isolate was included. Accordingly, blood isolates from 13 patients were excluded from the analysis, which resulted in the final number of 101 invasive GBS isolates. In the case of duplicate isolates from a woman in the colonisation group, only the first isolate was included in the analysis (one isolate was excluded, which resulted in the final number of 70 colonising isolates). Finally, invasive isolates were divided into 2 subgroups based on the year of isolation: the early isolates (isolated 2001-2011; isolates from the laboratory in Ljubljana lacking) and the late isolates (isolated 2012-2018) (Supplementary Fig. 1). This was mainly performed to examine changes in the Slovenian GBS population and especially if the number and proportion of serotype III and GBS CC-17 isolates increased over time. However, it was also performed because national coverage of GBS isolates was only available from 2012 and onwards. The study was approved by the National Medical Ethics Committee in Slovenia (KME 54/07/15).

\section{Phenotypic characterisation}

Phenotypic characterisation was performed at the Institute of Microbiology and Immunology, Ljubljana, Slovenia. Species identification was performed by MALDI-TOF mass spectrometry (Bruker Daltonics, Bremen, Germany). Antibiotic susceptibility testing was performed and interpreted according to the EUCAST Clinical Breakpoint Tables v10.0 (www.eucast.org), using the disc diffusion method for vancomycin, levofloxacin, trimethoprim-sulfamethoxazole, erythromycin, clindamycin, and tetracycline on MuellerHinton fastidious agar. Minimum inhibitory concentrations (MICs) of benzylpenicillin and ampicillin were determined using the Etest (bioMérieux, Marcy l'Etoile, France) on Mueller-Hinton fastidious agar. Serotyping was conducted with ImmuLex Strep-B-Latex test (SSI Diagnostica, Hillerød, Danmark), as previously described [15]. After WGS-based 'serotyping' was available, all discrepant isolates were retested for the final result.

\section{Genomic characterisation}

Genomic characterisation was performed at the WHO Collaborating Centre for Gonorrhoea and other STIs, Örebro University Hospital, Örebro, Sweden. Briefly, all isolates were grown from frozen stocks on blood agar media at $36^{\circ} \mathrm{C}$ and bacterial suspensions were subjected to $60 \mathrm{~min}$ of lysis at $37^{\circ} \mathrm{C}$ after adding an enzyme cocktail [16] containing lysozyme $(20 \mathrm{mg} / \mathrm{mL})$, mutanolysin $(250$ $\mathrm{U} / \mathrm{mL}$ ), and lysostaphin $(20 \mathrm{U} / \mathrm{mL})$ (Sigma-Aldrich, Saint Louis, Missouri, USA). Extraction of genomic DNA was performed using QIAsymphony DSP Virus/Pathogen Midi Kit (Qiagen, Hilden, Germany). Libraries were prepared using Nextera XT library preparation kit and WGS was performed on the Illumina MiSeq System (Illumina, San Diego, CA, USA) using Miseq Reagent kit V3 (600-cycle) producing $300 \mathrm{bp}$ paired-end reads for each isolate with an average coverage of $126 \times$ per base (range: $82-180 \times$ ). Reads were aligned to the chromosome of the S. agalactiae reference strain NEM316 (Genbank: NC_004368.1) using Burrows Wheeler Aligner (BWA) [17] with GATK indel realignment. Variant sites were identified from each isolate using bcftools (version 0.19) included in SAMtools (version 0.19) with default parameters [18] and filtered as described previously [19] to produce a multiple-sequence alignment.

De novo assembly was performed using CLC Genomics Workbench 12.0.1 and Velvet 1.2.10 assembler (https:// github.com/dzerbino/velvet/tree/master) for confirmation [20]. MLST was performed from draft genomes and using the MLST tool (https://github.com/tseemann/mlst) as well as PubMLST (https://pubmlst.org). Clonal complexes were assigned using eBURST (http://eburst.mlst.net) [21] Other genes of interest were extracted and characterised from the genome sequences using BLAST (https://blast. ncbi.nlm.nih.gov) and an in silico "PCR" method (https:// github.com/egonozer/in_silico_pcr). WGS-based 'serotyping' was performed by analysing the variable region of the cps region [22].

Characterisations of surface and pathogenicity/virulence genes were performed in silico from draft genomes. Pili, ALP family (alp1, rib, R28, alpha), C5a peptidase $(s c p B)$, laminin/fibrinogen-binding proteins $(\operatorname{lm} b, f b s A, f b s B)$ and other adhesins (bibA, $h v g A, \quad s r r-1, \quad s r r-2)$ genes were analysed. Previously described Pili, ALP, srr and $h v g A$ genotypes [22] were determined using BLAST. For the genotypic characterisation of $s c p B, \operatorname{lm} b, f b s A$ and $f b s B$, gene sequences were extracted from draft genomes, aligned with MUSCLE algorithm [23], and arbitrarily named using consecutive allele numbers. Neighbor-joining (NJ) trees were then constructed using SeaView 4.7 [24] and major clades were classified into allele numbers.

Phylogeny was achieved by mapping the reads to the reference genome of S. agalactiae NEM316 (NC_004368.1) using the bwa tool (http://bio-bwa.sourceforge.net) and constructing maximum-likelihood (ML) phylogenomic tree from the alignment using the generalized time reversible (GTR) substitution model and gamma distribution in the RAxML tool with 100 bootstraps (https://github.com/stama tak/standard-RAxML) [25]. Additionally, alignments were generated masked for recombination using the Gubbins tool (https:/github.com/sanger-pathogens/gubbins [26]) and a second ML phylogenetic tree excluding regions of recombination was constructed. Phylogenetic trees were visualized with metadata using Microreact (https://microreact. 
org) and Phandango (https://jameshadfield.github.io/ phandango/\#/) [27, 28].

Raw sequence data were deposited at the European Nucleotide Archive (ENA); project accession number PRJEB35421.

\section{Statistical analysis}

Descriptive statistics were used for sample characterisation. Chi-squared test was used for category proportion comparison between groups and subgroups. Significance was defined as $p$-values $<0.05$.

\section{Results}

\section{Patients and bacterial isolates}

Basic patient characteristics are shown in Table 1. Briefly, $42.6 \%(n=43)$ of patients were females, $41.5 \%$

Table 1 Basic patient information

\begin{tabular}{|c|c|}
\hline Groups and categories & Number (\%) \\
\hline \multicolumn{2}{|l|}{ PATIENTS } \\
\hline Invasive disease & $101(100)$ \\
\hline \multicolumn{2}{|l|}{ Gender } \\
\hline Female & $43(42.6)$ \\
\hline Male & $58(57.4)$ \\
\hline \multicolumn{2}{|l|}{ Gestation $(n=94)$} \\
\hline Preterm (<37 weeks) & $39(41.5)$ \\
\hline Term ( $\geq 37$ weeks) & $55(58.5)$ \\
\hline \multicolumn{2}{|l|}{ Disease type ${ }^{a}$} \\
\hline Early-onset (EOD) & $42(41.6)$ \\
\hline Late-onset (LOD) & $55(54.5)$ \\
\hline Very late-onset (vLOD) & $4(4)$ \\
\hline \multicolumn{2}{|l|}{ Geographical location } \\
\hline Ljubljana & $42(41.6)$ \\
\hline Celje & $25(24.8)$ \\
\hline Maribor & $30(29.7)$ \\
\hline Koper & $4(4)$ \\
\hline \multicolumn{2}{|l|}{ Year of disease } \\
\hline 2001-2011 (early) & $31(30.7)$ \\
\hline 2012-2018 (late) & $70(69.3)$ \\
\hline Colonisation & $70(100)$ \\
\hline \multicolumn{2}{|l|}{ Age group } \\
\hline Age $\leq 30$ years & $35(50)$ \\
\hline Age $>30$ years & $35(50)$ \\
\hline \multicolumn{2}{|l|}{ Geographical location } \\
\hline Ljubljana & $70(100)$ \\
\hline \multicolumn{2}{|l|}{ Year sample collection } \\
\hline 2018 & $70(100)$ \\
\hline Total & $171(100)$ \\
\hline
\end{tabular}

${ }^{2}$ Disease type definition: EOD (1-7 days), LOD (8-90 days), vLOD (91-365 days)
( $n=39 / 94)$ were from preterm deliveries ( $<37$ weeks gestation), and 41.6\% $(n=42)$ had EOD. Altogether, 171 patients/isolates were included in the analysis, 101 from neonates/infants with IND (invasive) and 70 from consecutive pregnant women (colonising).

\section{Antimicrobial susceptibility testing}

All isolates were susceptible to benzylpenicillin, ampicillin, vancomycin, levofloxacin, and trimethoprimsulfamethoxazole. The susceptibility to both erythromycin and clindamycin was $>80 \%$ (Supplementary Table 2). Most $(87.2 \%, n=149)$ isolates were resistant to tetracycline; invasive isolates $(n=93,92.1 \%)$ resistant at higher frequency than colonising isolates $(n=56,80 \%)(p=0.02)$. None had elevated MICs $(>0.125 \mathrm{mg} / \mathrm{L})$ of benzylpenicillin or ampicillin.

\section{Phenotypic and molecular 'serotyping'}

A pairwise comparison of conventional phenotypic serotyping and molecular 'serotyping' is summarised in Supplementary Table 3. A serotype could be phenotypically determined for all isolates $(n=171)$, while 4 isolates $(2.3 \%)$ were non-typeable (NT) using the molecular method. Excluding the NT isolates, $87.4 \%(n=146)$ of serotype results were concordant between the two methods. Nine, 5 and 7 isolates assigned the phenotypic serotypes Ia, Ib and III, respectively, gave discordant results in the molecular typing. Molecular serotype combined with phenotypic serotype for the 4 NT isolates was used as a final result. Overall, 7 capsular serotypes were identified (Ia, Ib, II, III, IV, V, and VIII). Serotype III was the most common serotype overall (59.6\% of isolates), as well as among invasive isolates (74.3\%) and colonising isolates (38.6\%). However, the proportion of serotype III isolates was significantly higher among the invasive isolates compared to the colonising isolates $(p<0.001)$. The distribution of serotypes and CCs is depicted in Table 2.

\section{Multilocus sequence typing}

Twenty-eight STs were detected, of which 10 had previously not been described. Thirteen and 24 unique STs were detected among the invasive and colonising isolates, respectively, showing higher variability within the latter $(p<0.001)$. Altogether, the STs were grouped into 6 CCs and 4 singletons based on eBURST analysis. CC-17, CC23, CC-12, CC-1, and CC-19 included more than 10 isolates each. Overall, $\mathrm{CC}-17$ was the most common CC, including $53.2 \%(n=91)$ of isolates. CC-17 was more common among invasive versus colonising isolates (67.3 vs. $32.9 \%$; $p<0.001)$, and LOD versus EOD isolates $(81.4 \%$ vs. 47.6\%; $p<0.001$ ) (Supplementary Tables 4, 5 and 6). However, the proportion of CC-17 isolates was not significantly different $(p=0.187)$ in the early period $(58.1 \%)$ 
Table 2 Distribution of serotypes and multilocus sequence typing MLST) clonal complexes (CC) among Slovenian group B Streptococcus isolates from patients with invasive neonatal infection and colonised pregnant woman in 2001-2018. One isolate per patient is included in the analysis $(n=171)$

\begin{tabular}{|c|c|c|c|}
\hline $\begin{array}{l}\text { Serotype } \\
\text { Clonal } \\
\text { complex }\end{array}$ & $\begin{array}{l}\text { All isolates } \\
n=171 \\
\text { No. (\%) }\end{array}$ & $\begin{array}{l}\text { Invasive } \\
n=101 \\
\text { No. (\%) }\end{array}$ & $\begin{array}{l}\text { Colonising } \\
n=70 \\
\text { No. (\%) }\end{array}$ \\
\hline la & $21(12.3)$ & $8(7.9)^{a}$ & $13(18.6)^{\mathrm{a}}$ \\
\hline CC- -23 & $18(10.5)$ & 7 (6.9) & $11(15.7)$ \\
\hline$C C-1$ & $1(0.6)$ & & $1(1.4)$ \\
\hline CC-498 & $2(1.2)$ & $1(1)$ & $1(1.4)$ \\
\hline Ib & $12(7)$ & $7(6.9)$ & $5(7.1)$ \\
\hline CC-12 & $12(7)$ & $7(6.9)$ & $5(7.1)$ \\
\hline II & $14(8.2)$ & $2(2)$ & $12(17.1)$ \\
\hline CC-12 & $7(4.1)$ & $1(1)$ & $6(8.6)$ \\
\hline CC-19 & $5(2.9)$ & $1(1)$ & $4(5.7)$ \\
\hline CC-1 & $1(0.6)$ & & $1(1.4)$ \\
\hline Singleton & $1(0.6)$ & & $1(1.4)$ \\
\hline III & $102(59.6)$ & $75(74.3)^{b}$ & $27(38.6)^{b}$ \\
\hline CC-17 & $89(52)$ & $68(67.3)$ & $21(30)$ \\
\hline CC-19 & $8(4.7)$ & $6(5.9)$ & $2(2.9)$ \\
\hline CC-23 & $4(2.3)$ & $1(1)$ & $3(4.3)$ \\
\hline Singleton & $1(0.6)$ & & $1(1.4)$ \\
\hline IV & $2(1.2)$ & & $2(2.9)$ \\
\hline CC-17 & $2(1.2)$ & & $2(2.9)$ \\
\hline V & $19(11.1)$ & $9(8.9)$ & $10(14.3)$ \\
\hline CC-1 & $15(8.8)$ & $6(5.9)$ & $9(12.9)$ \\
\hline CC-19 & $1(0.6)$ & & $1(1.4)$ \\
\hline CC-498 & $1(0.6)$ & $1(1)$ & \\
\hline Singleton & $2(1.2)$ & $2(2)$ & \\
\hline VIII & $1(0.6)$ & & $1(1.4)$ \\
\hline CC-1 & $1(0.6)$ & & $1(1.4)$ \\
\hline Total & $171(100)$ & $101(100)$ & $70(100)$ \\
\hline
\end{tabular}

No. number

${ }^{\text {a }}$ Proportions of serotype la isolates among invasive and colonising isolates were significantly different $(p=0.037)$

bProportions of serotype III isolates among invasive and colonising isolates were significantly different $(p<0.001)$

compared to the late period (71.4\%) (Supplementary Table 7).

\section{Phylogeny and characterisation of pathogenicity/ virulence genes}

A SNP-based ML phylogenetic tree including metadata is shown in Fig. 1. Six clades with $\geq 5$ isolates could be distinguished within the 5 major CCs. CC-19 was represented by 2 clades characterised by different serotypes, i.e. II and III. The majority $(4 / 5,80 \%)$ of these serotype II isolates were colonising and the serotype III isolates were predominantly invasive $(n=7 / 9,78 \%)$. Overall, CC17 isolates were almost exclusively assigned serotype III and they were predominantly invasive. However, two colonising CC-17 isolates were of serotype IV. A high homogeneity of surface and pathogenicity/virulence factors was observed within the CCs. As almost one third (32.9\%) of non-invasive colonising isolates belonged to CC-17, it was difficult to compare the presence/absence of different pathogenicity/virulence factors between the invasive and colonising isolates. Typical profiles of pathogenicity/virulence factors of the 5 most common CCs are depicted in Table 3.

SNP-based ML phylogenetic tree was also constructed after excluding regions of abundant recombination using Gubbins [26] (Fig. 2).

A striking difference in frequency of recombination within CC-17 isolates compared to isolates of other CCs was observed (Fig. 2). This highlights the importance of horizontal gene transfer and recombination in GBS, especially among non-CC-17 strains. In contrast, the CC-17 hypervirulent clade had few regions prone to recombination.

\section{Discussion}

In this first molecular epidemiology and genomic study of GBS in Slovenia, we show a high prevalence of hypervirulent MLST CC-17 among invasive isolates (67.3\%), but also among contemporary colonising (32.9\%) isolates. The CC-17 isolates were relatively conserved genomically and mostly belonged to serotype III. Slovenian GBS isolates were uniformly susceptible to benzylpenicillin (MICs $\leq 0.125 \mathrm{mg} / \mathrm{L}$ ), whereas the resistance to erythromycin $(17 \%)$ and clindamycin $(16 \%)$ was comparable to that of other European countries [29, 30].

The concordance between phenotypic and molecular 'serotyping' methods was $87 \%$, suggesting imperfect but mainly sufficient typing using also sequencing methods, particularly in view of the increasing availability of WGS and other molecular methods [22]. This concordance is also in line with two recent studies, that is, describing 87-94\% concordance [31, 32]. Nevertheless, this suboptimal concordance is important to take into account when performing, for example, surveillance studies informing vaccine design. Overall, 7 serotypes were identified, with serotype III accounting for the majority of isolates $(60 \%)$. Serotype III isolates mostly belonged to CC-17 (52\%), but some were assigned CC-19 (4.7\%) and CC-23 (2.3\%). Serotype III was predominantly associated with invasive disease ( $74 \%$ of invasive isolates). Serotypes among colonising isolates were more evenly distributed, consistent with data from a recent meta-analysis [33]. 


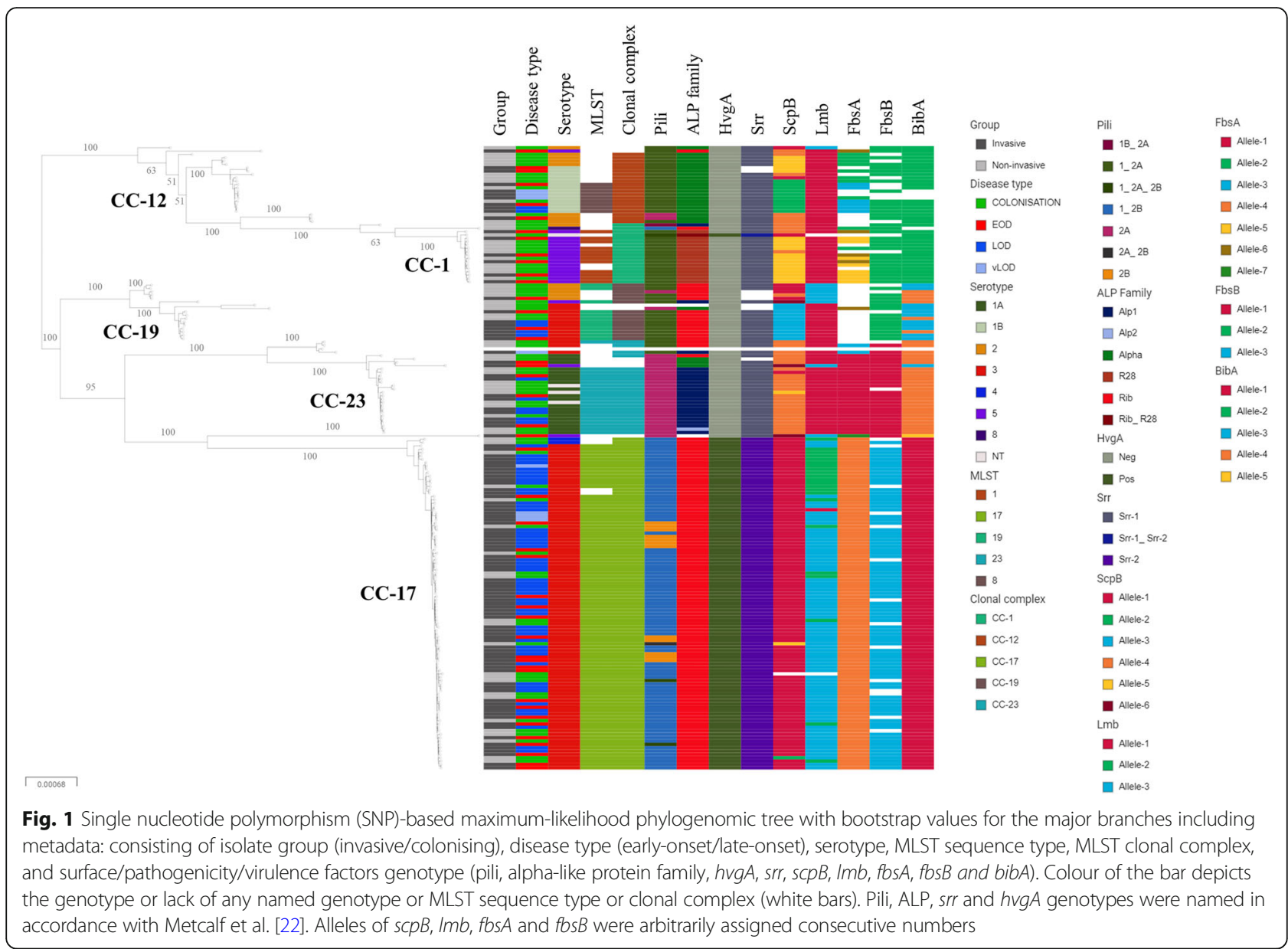

Table 3 Pathogenicity/virulence factors in group B Streptococcus isolates, belonging to the 5 major multilocus sequence typing (MLST) clonal complexes (CCS), cultured in Slovenia from 2001 to 2018. The most prevalent genotype within each CC and its proportion are shown

\begin{tabular}{|c|c|c|c|c|c|c|c|c|c|c|c|}
\hline $\begin{array}{l}\text { Clonal } \\
\text { complex }\end{array}$ & $\begin{array}{l}\text { Number } \\
\text { (\%) }\end{array}$ & $\begin{array}{l}\text { Capsule } \\
\text { (cps) } \\
{[22]}\end{array}$ & $\begin{array}{l}\text { Pili } \\
\text { [22] }\end{array}$ & $\begin{array}{l}\text { ALP family } \\
\text { (alp1, alpha, } \\
\text { rib, R28) [22] }\end{array}$ & $\begin{array}{l}\text { C5a } \\
\text { peptidase } \\
(\operatorname{scp} B)\end{array}$ & $\begin{array}{l}\text { Laminin- } \\
\text { binding } \\
\text { protein } \\
(\operatorname{Imb})\end{array}$ & $\begin{array}{l}\text { Fibrinogen- } \\
\text { binding } \\
\text { protein A } \\
(f b s A)\end{array}$ & $\begin{array}{l}\text { Fibrinogen- } \\
\text { binding } \\
\text { protein B } \\
(\text { fbs } B)\end{array}$ & $\begin{array}{l}\text { Serine-rich } \\
\text { proteins } \\
\text { (srr) [22] }\end{array}$ & $\begin{array}{l}\text { GBS } \\
\text { immunogenic } \\
\text { adhesin A (bibA) }\end{array}$ & $\begin{array}{l}\text { Hypervirulent } \\
\text { GBS adhesin } \\
\text { (hvgA allele) }\end{array}$ \\
\hline & & \multicolumn{10}{|c|}{ Genotype (\%) } \\
\hline CC-1 & $\begin{array}{l}18 \\
(10.5)\end{array}$ & $\begin{array}{l}V \\
(83.3)\end{array}$ & $\begin{array}{l}1,2 \mathrm{~A} \\
(83.3)\end{array}$ & $\begin{array}{l}\text { R28 } \\
(83.3)\end{array}$ & $\begin{array}{l}\text { allele-5 } \\
(72.2)\end{array}$ & $\begin{array}{l}\text { allele-1 } \\
(94.4)\end{array}$ & $\begin{array}{l}\text { allele-5 } \\
(44.4)\end{array}$ & $\begin{array}{l}\text { allele-2 } \\
(88.9)\end{array}$ & $\begin{array}{l}\text { srr-1 } \\
(94.4)\end{array}$ & $\begin{array}{l}\text { allele-2 } \\
(94.4)\end{array}$ & $\begin{array}{l}\text { neg } \\
(94.4)\end{array}$ \\
\hline CC-12 & $\begin{array}{l}19 \\
(11.1)\end{array}$ & $\begin{array}{l}\mathrm{lb} \\
(63.2)\end{array}$ & $\begin{array}{l}1,2 \mathrm{~A} \\
(89.5)\end{array}$ & $\begin{array}{l}\text { alpha } \\
(100)\end{array}$ & $\begin{array}{l}\text { allele-2 } \\
(42.1)\end{array}$ & $\begin{array}{l}\text { allele-1 } \\
(100)\end{array}$ & $\begin{array}{l}\text { allele-2 } \\
(36.8)\end{array}$ & $\begin{array}{l}\text { allele-2 } \\
(68.4)\end{array}$ & $\begin{array}{l}\text { srr-1 } \\
(89.5)\end{array}$ & $\begin{array}{l}\text { allele-2 } \\
(94.7)\end{array}$ & $\begin{array}{l}\text { neg } \\
(100)\end{array}$ \\
\hline CC-17 & $\begin{array}{l}91 \\
(53.2)\end{array}$ & $\begin{array}{l}\text { III } \\
(97.8)\end{array}$ & $\begin{array}{l}1,2 \mathrm{~B} \\
(84.6)\end{array}$ & $\begin{array}{l}\text { rib } \\
(100)\end{array}$ & $\begin{array}{l}\text { allele-1 } \\
\text { (96.7) }\end{array}$ & $\begin{array}{l}\text { allele-3 } \\
\text { (74.7) }\end{array}$ & $\begin{array}{l}\text { allele-4 } \\
(100)\end{array}$ & $\begin{array}{l}\text { allele-3 } \\
(85.7)\end{array}$ & $\begin{array}{l}\text { srr-2 } \\
(100)\end{array}$ & $\begin{array}{l}\text { allele-1 } \\
(100)\end{array}$ & $\begin{array}{l}\text { pos } \\
(100)\end{array}$ \\
\hline CC-19 & $\begin{array}{l}14 \\
(8.2)\end{array}$ & $\begin{array}{l}\text { III } \\
(57.1)\end{array}$ & $\begin{array}{l}1,2 \mathrm{~A} \\
(92.9)\end{array}$ & $\begin{array}{l}\text { rib } \\
(92.9)\end{array}$ & $\begin{array}{l}\text { allele-3 } \\
\text { (57.1) }\end{array}$ & $\begin{array}{l}\text { allele-1 } \\
(57.1)\end{array}$ & $\begin{array}{l}\text { null } \\
(100)\end{array}$ & $\begin{array}{l}\text { allele-2 } \\
\text { (78.6) }\end{array}$ & $\begin{array}{l}\text { srr-1 } \\
(78.6)\end{array}$ & $\begin{array}{l}\text { allele-3 } \\
\text { (57.1) }\end{array}$ & $\begin{array}{l}\text { neg } \\
(100)\end{array}$ \\
\hline CC-23 & $\begin{array}{l}22 \\
(12.9)\end{array}$ & $\begin{array}{l}\text { la } \\
(81.8)\end{array}$ & $\begin{array}{l}2 \mathrm{~A} \\
(86.4)\end{array}$ & $\begin{array}{l}\text { alp1 } \\
\text { (81.8) }\end{array}$ & $\begin{array}{l}\text { allele-4 } \\
\text { (90.9) }\end{array}$ & $\begin{array}{l}\text { allele-1 } \\
(100)\end{array}$ & $\begin{array}{l}\text { allele-1 } \\
(86.4)\end{array}$ & $\begin{array}{l}\text { allele-1 } \\
(90.9)\end{array}$ & $\begin{array}{l}\text { srr-1 } \\
(100)\end{array}$ & $\begin{array}{l}\text { allele-4 } \\
(100)\end{array}$ & $\begin{array}{l}\text { neg } \\
(100)\end{array}$ \\
\hline
\end{tabular}

ALP alpha-like proteins, neg negative, pos positive

Pili, ALP, srr and hvgA genotypes were named in accordance with Metcalf et al. [22]. Alleles of $s c p B, \operatorname{Imb}, f b s A$ and $f b s B$ were arbitrarily assigned consecutive numbers 


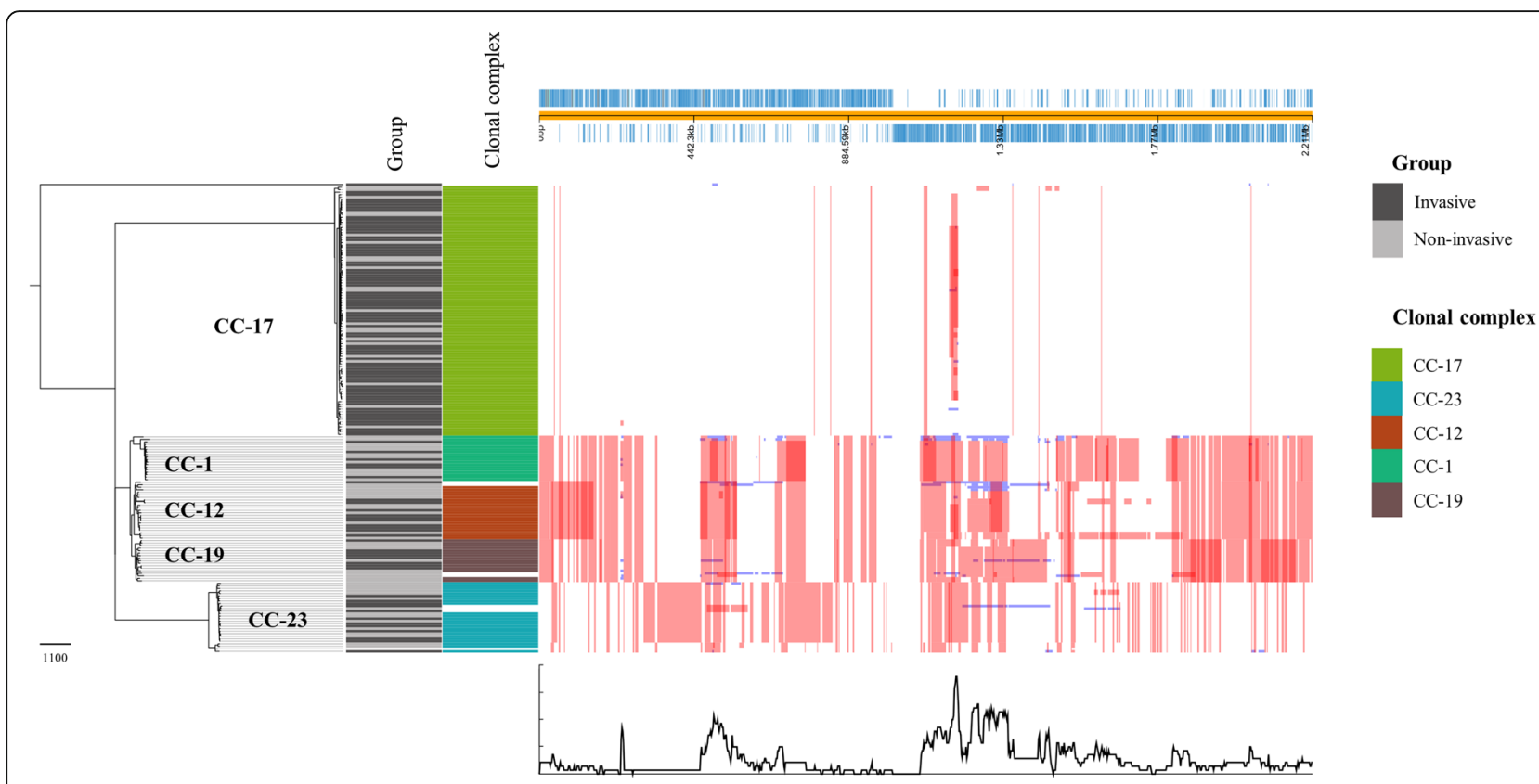

Fig. 2 Single nucleotide polymorphism (SNP)-based maximum-likelihood phylogenomic tree after regions of recombination have been excluded using Gubbins [26]. Group (invasive/non-invasive) and MLST clonal complex are described for each isolate and white bars depict isolates that do not belong to any of the five named major MLST clonal complexes. Genomic regions with high frequency of recombination are mapped to the reference genome of Streptococcus agalactiae NEM316 (annotated in blue on top). Each row represents an isolate and the columns relate to bases in the reference genome. The red columns are recombinations shared by multiple isolates and occuring in the internal branches. The blue columns are recombinations in the terminal branch and represented by unique isolates

GBS isolates in our study displayed a high level of genomic diversity with 28 MLST STs detected, 9 of which had not been described previously. The diversity was larger among the colonising isolates. Nevertheless, CC-17 comprised more than half of all isolates and was more common among the invasive and LOD isolates. This hypervirulent clone also showed a trend towards higher prevalence among the late subgroup of isolates (20122018) (58\% vs. $71 \%$ ), similar to a study from the Netherlands [13]. CC-17 had a characteristic profile of pathogenicity/virulence factors that included serotype III, pili 1-2B, ALP family $r i b, s c p B$ allele-1, $f b s A$ allele-4, $f b s B$ allele-3, srr-2, $b i b A$ allele-1 and $h v g A$ positive. These results are in-line with several previous studies [7-9, 13, 27].

The genome organisation of the frequently invasive CC-17 isolates was highly conserved with few recombination prone regions. This may indicate that $\mathrm{CC}-17$ has already experienced an evolutionary selection to increase fitness for survival and pathogenicity/virulence. In contrast, non-CC-17 isolates were recombination prone, highlighting the importance of recombination and horizontal gene transfer in GBS evolution [12]. Interestingly, CC-1, CC-12 and CC-19, which are predominantly colonising $\mathrm{CCs}$, belonged to the same clade after the regions of recombination were removed (Fig. 2).
The limitations of the present study included that we were not able to include isolates from all cases of IND due to the unavailability of GBS isolates from 2001 to 2010 in the largest Slovenian laboratory (in Ljubljana). Furthermore, colonising isolates were available only from 2018 and the laboratory in Ljubljana. Finally, we had limited clinical data from the IND cases. However, despite these limitations, a relatively large number of IND cases, isolates and standard genomic analysis tools provided us with detailed and reliable baseline information about the GBS population structure in Slovenia.

\section{Conclusions}

A high prevalence of hypervirulent $\mathrm{CC}-17$ isolates, with low genomic diversities and characteristic profile of pathogenicity/virulence factors, was detected among invasive neonatal and colonising GBS isolates from pregnant women in Slovenia. This is the first genomic characterisation of GBS isolates in Slovenia and provides valuable microbiological and genomic baseline data regarding the invasive and colonising GBS population in Slovenia. Continuous genomic surveillance of GBS infections is crucial to analyse the impact of IND prevention strategies on the population structure of GBS locally, nationally and internationally. 


\section{Supplementary Information}

The online version contains supplementary material available at https://doi. org/10.1186/s12879-020-05599-y.

\section{Additional file 1: Supplementary Table 1. Number of births in} Slovenia during the years 2002-2018 and calculated representativeness of the sample based on the estimated incidence of invasive neonatal disease (IND) of $0.7 / 1000$ births from reference 3. Supplementary Table 2. Antimicrobial susceptibility of Slovenian invasive neonatal and colonising pregnant women isolates of group B Streptococcus from early (2001-2011) and late (2012-2018) period ( $n=171)$. Supplementary Table 3. Pairwise comparison of conventional phenotypic serotyping and molecular 'serotyping' results among invasive and non-invasive isolates of group B Streptococcus from early (2001-2011) and late (20122018) period $(n=171)$. Supplementary Table 4. Distribution of multilocus sequence typing (MLST) sequence types (STs) and clonal complexes (CCs) among Slovenian group B Streptococcus isolates overall and among isolates from infants with invasive neonatal disease (2001-2018) and pregnant woman with colonisation (2018. Supplementary Table 5. Distribution of multilocus sequence typing (MLST) and clonal complexes (CCS) among Slovenian group B Streptococcus isolates overall and among isolates from patients with invasive neonatal disease (2001-2018) and pregnant woman with colonisation (2018). Supplementary Table 6. Distribution of multilocus sequence typing (MLST) and clonal complexes (CCS) among invasive neonatal group B Streptococcus isolates from Slovenia within two groups based on disease onset. Supplementary

Table 7. Distribution of multilocus sequence typing (MLST) and clonal complexes (CCs) among invasive neonatal group B Streptococcus isolates from Slovenia within two groups based on time period of disease. Supplementary Fig. 1. Distribution of invasive group B Streptococcus isolates $(n=114)$ from different laboratories in Slovenia from 2001 to 2018. Unfortunately, during 2001-2010, isolates from the largest laboratory (in Ljubljana) were not preserved so whole genome sequencing of those could not be performed. LJ: Ljubljana; MB: Maribor; CE: Celje; KP: Koper. Supplementary Fig. 2. eBURST analysis of 28 multilocus sequence typing (MLST) sequence types (STs) identifying six clonal complexes (CCS) and four singletons, among Slovenian group B Streptococcus isolates from infants with invasive neonatal disease (2001-2018) and pregnant woman with colonisation (2018)

\section{Abbreviations}

ALP: Alpha like proteins; Bib: GBS immunogenic adhesins; CC: Clonal complex; CSF: Cerebrospinal fluid; EOD: Early onset disease; Fbs: Fibrinogen binding proteins; GBS: Group B Streptococcus; HvgA: Hypervirulent GBS adhesin; IND: Invasive neonatal disease; Lmb: Laminin binding protein; LOD: Late onset disease; MALDI-TOF: Matrix assisted laser desorption/ ionization-time of flight; MIC: Minimum inhibitory concentration; MLST: Multilocus sequence typing; NT: Non-typeable; ScpB: C5a peptidase; SNP: Single nucleotide polymorphism; Srr: Serine rich protein; ST: Sequence type; vLOD: Very late onset disease; WGS: Whole genome sequencing

\section{Acknowledgements}

We would like to thank Tinka Lampe for her help with the phenotypic characterisation of the isolates. Special thanks go to Manica Mueller Premru for her invaluable contribution and support of the study.

\section{Authors' contributions}

TP, DG, Al, SJ, MU designed the study. TP, ML, ŠG, LKC, MBI, AR, PF and JLK collected the patients and samples. TP, DG, MU, SJ analysed the data. TP and SJ wrote the first draft of manuscript. All authors were involved in finalising the manuscript and approved the final version of the manuscript.

\section{Funding}

The study was supported by the Örebro County Council Research Committee and the Foundation for Medical Research at Örebro University Hospital, Örebro, Sweden. Open Access funding provided by Örebro University.

\section{Availability of data and materials}

The datasets used and/or analysed during the current study are available from the corresponding author on reasonable request.

Ethics approval and consent to participate

The study was approved by the National Medical Ethics Committee (KME 54/ 07/15).

Consent for publication

Not applicable.

\section{Competing interests}

The authors declare that they have no competing interests.

\section{Author details}

'Department of Perinatology, University Medical Centre Ljubljana, Ljubljana, Slovenia. ${ }^{2} \mathrm{WHO}$ Collaborating Centre for Gonorrhoea and other STIS, National Reference Laboratory for STIs, Department of Laboratory Medicine, Microbiology, Örebro University, SE-70185 Örebro, Sweden. ${ }^{3}$ National Laboratory for Health, Environment and Food, Maribor, Slovenia.

${ }^{4}$ Department of Neonatology, Division of Pediatrics, University Medical Centre Ljubljana, Ljubljana, Slovenia. ${ }^{5}$ Chair of Pediatrics, Faculty of Medicine, University of Ljubljana, Ljubljana, Slovenia. ${ }^{6}$ Institute for Microbiology and Immunology, Medical Faculty, University of Ljubljana, Ljubljana, Slovenia.

Received: 7 May 2020 Accepted: 9 November 2020

Published online: 16 December 2020

\section{References}

1. Edmond KM, Kortsalioudaki C, Scott S, Schrag SJ, Zaidi AKM, Cousens S, et al. Group B streptococcal disease in infants aged younger than 3 months: systematic review and meta-analysis. Lancet. 2012;379:547-56.

2. Verani JR, McGee L, Schrag SJ. Division of Bacterial Diseases, National Center for Immunization and Respiratory Diseases, Centers for Disease Control and Prevention (CDC). Prevention of perinatal group B streptococcal disease-revised guidelines from CDC, 2010. MMWR Recomm Rep. 2010:59:1-36.

3. Lasič M, Lučovnik M, Kaparič T, Ciringer M, Krivec JL, Fister $P$, et al. Invazivne okužbe novorojenčkov z bakterijo Streptococcus agalactiae v Sloveniji, 2003-2013. Zdrav Vestn. 2017;86:493-506 [In Slovenian].

4. Lindahl G, Stålhammar-Carlemalm M, Areschoug T. Surface proteins of Streptococcus agalactiae and related proteins in other bacterial pathogens. Clin Microbiol Rev. 2005;18:102-27

5. Furfaro LL, Chang BJ, Payne MS. Perinatal Streptococcus agalactiae epidemiology and surveillance targets. Clin Microbiol Rev. 2018;31: e00049-18.

6. Shabayek S, Spellerberg B. Group B streptococcal colonization, molecular characteristics, and epidemiology. Front Microbiol. 2018:9:437. https://doi. org/10.3389/fmicb.2018.00437.

7. Maisey HC, Doran KS, Nizet V. Recent advances in understanding the molecular basis of group B Streptococcus virulence. Expert Rev Mol Med. 2008;10:e27. https://doi.org/10.1017/S1462399408000811.

8. Six A, Bellais S, Bouaboud A, Fouet A, Gabriel C, Tazi A, et al. Srr2, a multifaceted adhesin expressed by ST-17 hypervirulent group B Streptococcus involved in binding to both fibrinogen and plasminogen. Mol Microbiol. 2015;97:1209-22.

9. Tazi A, Disson O, Bellais S, Bouaboud A, Dmytruk N, Dramsi S, et al. The surface protein HvgA mediates group B Streptococcus hypervirulence and meningeal tropism in neonates. J Exp Med. 2010:207:2313-22.

10. Maiden MC, Bygraves JA, Feil E, Morelli G, Russell JE, Urwin R, et al. Multilocus sequence typing: a portable approach to the identification of clones within populations of pathogenic microorganisms. Proc Natl Acad Sci U S A. 1998;95:3140-5.

11. Schürch AC, Arredondo-Alonso S, Willems RJL, Goering RV. Whole genome sequencing options for bacterial strain typing and epidemiologic analysis based on single nucleotide polymorphism versus gene-by-gene-based approaches. Clin Microbiol Infect. 2018;24:350-4.

12. Da Cunha V, Davies MR, Douarre P-E, Rosinski-Chupin I, Margarit I, Spinali S, et al. Streptococcus agalactiae clones infecting humans were selected and fixed through the extensive use of tetracycline Nat Commun 2014:5:4544. https://doi.org/10.1038/ncomms5544. 
13. Bekker V, Bijlsma MW, van de Beek D, Kuijpers TW, van der Ende A. Incidence of invasive group B streptococcal disease and pathogen genotype distribution in newborn babies in the Netherlands over 25 years: a nationwide surveillance study. Lancet Infect Dis. 2014;14:1083-9.

14. Lučovnik M, Tul Mandić N, Lozar Krivec J, Dolinar U, Jeverica S. Prevalenca kolonizacije z bakterijo Streptococcus agalactiae pri nosečnicah v Sloveniji v obdobju 2013-2014. Zdrav Vestn. 2016;85:393-400 [In Slovenian].

15. Slotved HC, Elliott J, Thompson T, Konradsen HB. Latex assay for serotyping of group B Streptococcus isolates. J Clin Microbiol. 2003:41:4445-7.

16. Gill C, van de Wijgert JHHM, Blow F, Darby AC. Evaluation of lysis methods for the extraction of bacterial DNA for analysis of the vaginal microbiota. PLoS One. 2016;11:e0163148-16.

17. Li H, Durbin R. Fast and accurate short read alignment with burrowswheeler transform. Bioinformatics. 2009;25:1754-60.

18. Li H, Handsaker B, Wysoker A, Fennell T, Ruan J, Homer N, et al. The sequence alignment/map format and SAMtools. Bioinformatics. 2009;25: 2078-9.

19. Harris SR, Feil EJ, Holden MT, Quail MA, Nickerson EK, Chantratita N, et al. Evolution of MRSA during hospital transmission and intercontinental spread. Science. 2010;327:469-74.

20. Zerbino DR, Birney E. Velvet: algorithms for de novo short read assembly using de Bruijn graphs. Genome Res. 2008;18:821-9.

21. Feil EJ, Li BC, Aanensen DM, Hanage WP, Spratt BG. eBURST: inferring patterns of evolutionary descent among clusters of related bacterial genotypes from multilocus sequence typing data. J Bacteriol. 2004;186: 1518-30.

22. Metcalf BJ, Chochua S, Gertz RE Jr, Hawkins PA, Ricaldi J, Li Z, et al. Shortread whole genome sequencing for determination of antimicrobial resistance mechanisms and capsular serotypes of current invasive Streptococcus agalactiae recovered in the United States. Clin Microbiol Infect. 2017;23:574.e7-14.

23. Edgar RC. MUSCLE: multiple sequence alignment with high accuracy and high throughput. Nucleic Acids Res. 2004;32:1792-7.

24. Gouy M, Guindon S, Gascuel O. SeaView version 4: a multiplatform graphical user interface for sequence alignment and phylogenetic tree building. Mol Biol Evol. 2010;27:221-4.

25. Stamatakis A. RAXML version 8: a tool for phylogenetic analysis and postanalysis of large phylogenies. Bioinformatics. 2014;30:1312-3.

26. Croucher NJ, Page AJ, Connor TR, Delaney AJ, Keane JA, Bentley SD, et al. Rapid phylogenetic analysis of large samples of recombinant bacterial whole genome sequences using Gubbins. Nucleic Acids Res. 2015;43(3):e15.

27. Argimón S, Abudahab K, Goater RJE, Fedosejev A, Bhai J, Glasner C, et al. Microreact: visualizing and sharing data for genomic epidemiology and phylogeography. Microb Genom. 2016;2:e000093.

28. Hadfield J, Croucher NJ, Goater RJ, Abudahab K, Aanensen DM, Harris SR. Phandango: an interactive viewer for bacterial population genomics. Bioinformatics. 2017;34:292-3.

29. Barcaite E, Bartusevicius A, Tameliene R, Kliucinskas M, Maleckiene L, Nadisauskiene R. Prevalence of maternal group B streptococcal colonisation in European countries. Acta Obstet Gynecol Scand. 2008:87:260-71.

30. Joubrel C, Tazi A, Six A, Dmytruk N, Touak G, Bidet P, et al. Group B Streptococcus neonatal invasive infections, France 2007-2012. Clin Microbiol Infect. 2015;21:910-6.

31. Kapatai G, Patel D, Efstratiou A, Chalker VJ. Comparison of molecular serotyping approaches of Streptococcus agalactiae from genomic sequences. BMC Genomics. 2017;18:D7-11.

32. Sheppard AE, Vaughan A, Jones N, Turner P, Turner C, Efstratiou A, et al. Capsular typing method for Streptococcus agalactiae using whole-genome sequence data. J Clin Microbiol. 2016:54:1388-90.

33. Russell NJ, Seale AC, O'Sullivan C, Le Doare K, Heath PT, Lawn JE, et al. Risk of early-onset neonatal group B streptococcal disease with maternal colonization worldwide: systematic review and meta-analyses. Clin Infect Dis. 2017;65(suppl_2):S152-9.

\section{Publisher's Note}

Springer Nature remains neutral with regard to jurisdictional claims in published maps and institutional affiliations.

\section{Ready to submit your research? Choose BMC and benefit from:}

- fast, convenient online submission

- thorough peer review by experienced researchers in your field

- rapid publication on acceptance

- support for research data, including large and complex data types

- gold Open Access which fosters wider collaboration and increased citations

- maximum visibility for your research: over $100 \mathrm{M}$ website views per year

At BMC, research is always in progress.

Learn more biomedcentral.com/submissions 